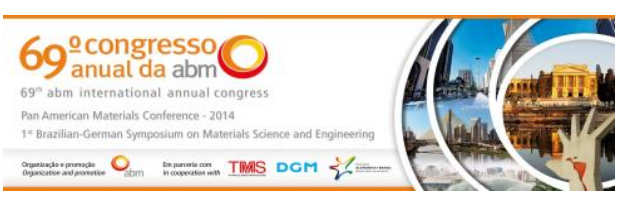

Tema: Metalurgia física e comportamento de materiais em temperaturas elevadas

\title{
ANÁLISE DA INFLUÊNCIA DA VELOCIDADE DE LINGOTAMENTO NA TRANSFERÊNCIA DE CALOR DURANTE A SOLIDIFICAÇÃO DE AÇOS ESPECIAIS*
}

\begin{abstract}
Bruna Brito Freitas ${ }^{1}$ Wagner Viana Bielefeldt ${ }^{2}$

Resumo

O lingotamento contínuo de tarugos é um processo extremamente complexo dependente de variáveis que influenciam diretamente na qualidade do aço lingotado e na produtividade. Geralmente essa influência é conflituosa. É necessário conhecer melhor os parâmetros de processo para compreender seus efeitos naquilo que é a base do lingotamento contínuo: a transferência de calor na interface metal/molde. Foram levantados dados de temperatura durante o lingotamento de diversas corridas de aços em uma planta de aços longos especiais. As medidas de temperatura das paredes do molde da máquina LC foram obtidas, utilizando-se termopares estrategicamente posicionados ao longo do comprimento do molde e nas suas faces. Através da obtenção dos valores de temperatura desses termopares e do levantamento dos dados de processo de cada corrida monitorada, foi possível correlacionar a influência da velocidade com a transferência de calor na interface metal/molde. Por fim, os resultados mostram que o aumento da velocidade de lingotamento gera um aumento na transferência de calor.
\end{abstract}

Palavras-chave: Lingotamento contínuo; Gap; Transferência de calor; Velocidade de lingotamento.

\section{INFLUENCE OF CASTING SPEED ON HEAT TRANSFER DURING SPECIAL} \section{STEEL SOLIDIFICATION}

\section{Abstract}

The continuous casting of billets is a highly complex process that depends on a large number of variables. These variables directly influence steel quality and productivity in a manner that is often controversial. Greater knowledge of the process parameters is needed in order to better understand their effects on the basis of continuous casting: metal/mold interfacial heat transfer. Temperature data were obtained during several steel heat castings in a special steel plant. The temperature of the mold walls was measured using thermocouples strategically positioned along the length of the mold and its faces. The temperatures and process data of the heats were used to correlate the influence of casting speed with heat transfer in the metal/mold interface. Finally, the results show that raising the casting speed produces an increase in heat transfer.

Keywords: Continuous casting; Gap; Heat transfer; Casting speed.

1 Engenheiro Metalúrgico. Programa de Pós-Graduação em Engenharia de Minas, Metalúrgica e de Materiais, UFRGS, Porto Alegre, RS, Brasil.

2 Engenheiro Metalúrgico. Professor Doutor, PPGE3M, UFRGS, Porto Alegre, RS, Brasil.

\footnotetext{
* Contribuição técnica ao 69을 Congresso Anual da ABM - Internacional e ao 14ํㅡㄹ ENEMET - Encontro Nacional de Estudantes de Engenharia Metalúrgica, de Materiais e de Minas, 21 a 25 de julho de 2014, São Paulo, SP, Brasil.
} 


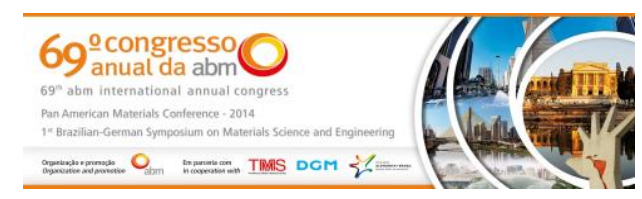

\section{INTRODUÇÃO}

O mercado mundial está se desenvolvendo continuamente em todos os segmentos, em especial na área siderúrgica. Dentro deste cenário, é necessário que as usinas siderúrgicas apresentem bons níveis de desempenho e qualidade para manter um alto nível de competitividade. No caso de usinas de aços especiais, o foco principal é dado à qualidade dos produtos e, na aciaria, uma área de influência decisiva neste quesito é o lingotamento contínuo.

O lingotamento contínuo tem como objetivo converter o aço líquido de uma dada composição química em uma peça sólida, com uma determinada forma e tamanho, através de uma série de operações [1]. Dependendo da geometria, o produto do lingotamento contínuo pode ser um tarugo, um bloco, uma placa ou ainda um perfil.

A solidificação do aço durante o lingotamento é obtida em três etapas bem distintas, que governam a solidificação do metal. A primeira etapa ocorre pelo contato do aço líquido com o molde de cobre resfriado a água, chamada zona de resfriamento primário ou região do molde [2,3]. Esta etapa é determinante para a qualidade superficial e a produtividade, pois é onde forma-se a casca sólida inicial. É importante na produtividade porque o molde deve solidificar uma casca sólida espessa o suficiente para suportar o metal líquido do interior do veio [1]. Da mesma forma, para manter qualidade superficial é crucial ter controle perante a região do menisco [4]. Quanto mais rápida for essa solidificação, mais rápida pode ser a velocidade de lingotamento, aumentando a produtividade. Logo, a velocidade de lingotamento é um dos principais parâmetros a ser analisado. Esse parâmetro inicia no vazamento do metal líquido para o molde e segue até etapa de corte. Tem estreita relação com o fluxo de calor, podendo gerar, quando não administrado corretamente, defeitos na superfície do lingote [5] e problemas como breakout [6].

$\mathrm{Na}$ segunda etapa do lingotamento realiza-se o borrifamento de água ou mistura de água e ar sobre a superfície de um lingote já com uma casca solidificada, no chamado resfriamento secundário, ou região dos chuveiros [7,8].

A terceira e última etapa ocorre com resfriamento pelo ar na chamada região de radiação livre. O principal fenômeno envolvido no processo de lingotamento contínuo é a transferência de calor, que ocorre nessas três etapas.

Qualquer massa que esteja a uma temperatura diferente do seu entorno realiza trocas térmicas a fim de alcançar o equilíbrio térmico. Esse fenômeno é explicado pela lei zero da termodinâmica. A segunda lei da termodinâmica explica que a propagação de calor é a transição de energia térmica que ocorre da maior para a menor temperatura. A energia térmica pode passar de um corpo para outro fundamentalmente por: condução, convecção e radiação. A transferência de calor que ocorre na superfície do tarugo é chamada de transferência Newtoniana de calor, sendo essa uma combinação das três formas citadas acima [9]. A atuação desses mecanismos de transferência de calor durante o processo de solidificação no molde do lingotamento contínuo e o perfil de temperaturas são apresentados na Figura 1.

Os mecanismos de transferência de calor mostrados na Figura 1 são representados, de forma quantitativa, através das temperaturas. É possível notar uma queda de temperatura acentuada na região entre o molde e a casca sólida, possivelmente devido à formação de um gap de ar.

\footnotetext{
* Contribuição técnica ao 69 Congresso Anual da ABM - Internacional e ao $14^{\circ}$ ENEMET - Encontro Nacional de Estudantes de Engenharia Metalúrgica, de Materiais e de Minas, 21 a 25 de julho de 2014, São Paulo, SP, Brasil.
} 


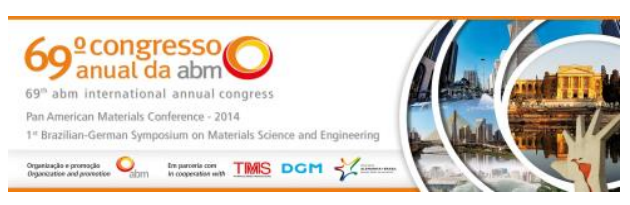

O objetivo desse trabalho é avaliar a transferência de calor devido à mudança na velocidade de lingotamento. Uma forma de quantificar esses dados é através da instrumentação do molde.

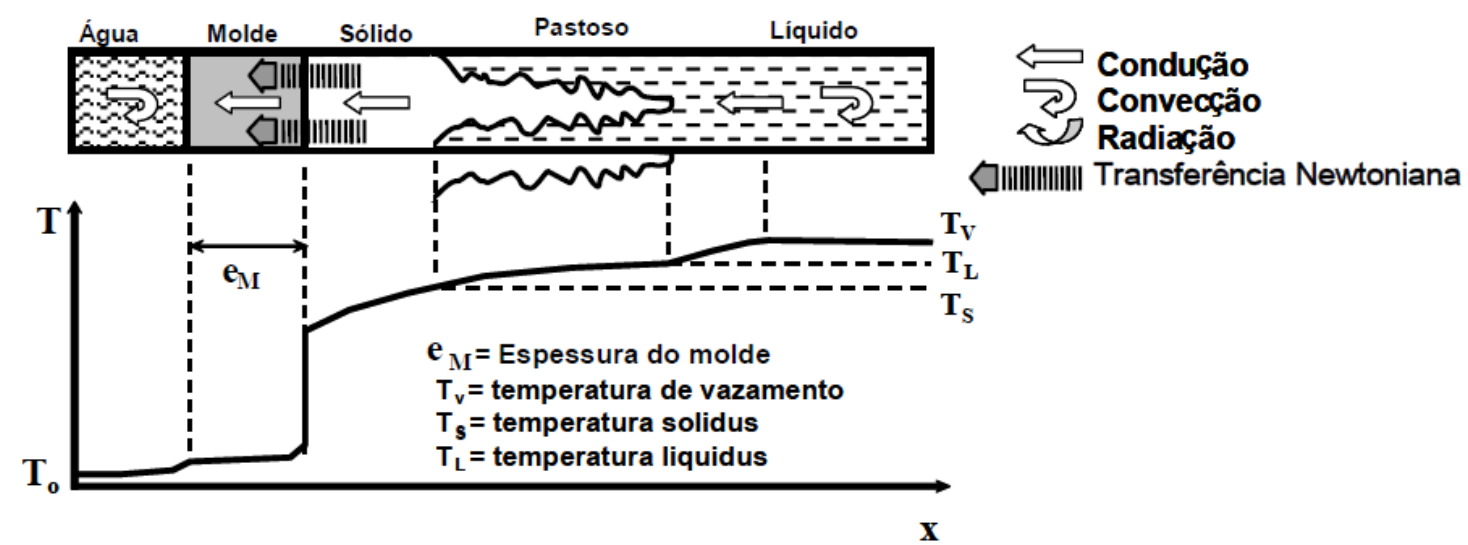

Figura 1. Mecanismos de transferência de calor no sistema metal/molde [10].

\section{MATERIAIS E MÉTODOS}

Para as avaliações das corridas foram analisados parâmetros de uma planta de lingotamento contínuo de aços especiais. Cada corrida tem em torno de 65 toneladas, o distribuidor tem capacidade para 15 t e a máquina de lingotamento opera com 3 veios. O sistema tem uma altura de aproximadamente 10 metros, medidos do solo até onde está o distribuidor. O raio da máquina é de 9 metros e a distância linear até o início do oxicorte é de 24 metros. O veio 3 foi instrumentado com termopares fixos no molde e pirômetros fixos e móveis na região dos chuveiros e de radiação livre, respectivamente, para análise da transferência de calor de 362 corridas. Dessas corridas, foram avaliadas três, com variações na velocidade de lingotamento, para análise desse parâmetro.

\subsection{Molde}

O molde utilizado tem seção $155 \times 155 \mathrm{~mm}$ e apresenta variações ao longo de seu comprimento, de forma que o contato com o tarugo seja otimizado. Além disso, os cantos possuem um raio de adoçamento, reduzindo as tensões de solidificação, como, por exemplo, minimizando o aparecimento de trincas off-corner. Para obtenção dos dados de temperatura, o mesmo foi instrumentado com 42 termopares distribuídos nos raios interno, externo e face lateral.

Os parâmetros termofísicos do molde foram obtidos via manuais técnicos do fabricante. A peça é fabricada de cobre e possui um revestimento interno constituído de uma camada depositada de cromo de aproximadamente $1 \mathrm{~mm}$, utilizada para melhorar a resistência ao desgaste do interior do molde.

São realizadas medições periódicas nas dimensões internas do molde, analisando distorções geométricas que podem levar a formação de defeitos e desgastes causados principalmente pela introdução da barra falsa na parte inferior do molde. Segundo o fabricante, temperaturas acima de $350^{\circ} \mathrm{C}$ podem alterar as características do molde.

\footnotetext{
* Contribuição técnica ao $69^{\circ}$ Congresso Anual da ABM - Internacional e ao 14ํㅡㄹ ENEMET - Encontro Nacional de Estudantes de Engenharia Metalúrgica, de Materiais e de Minas, 21 a 25 de julho de 2014, São Paulo, SP, Brasil.
} 


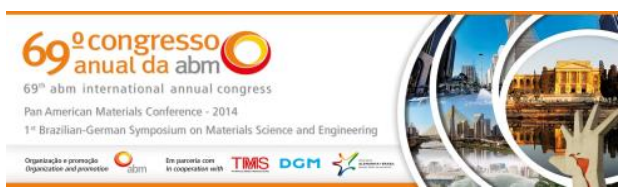

\subsection{Instrumentação com Termopares}

Para a instrumentação do molde foram distribuídos 42 termopares, do tipo $\mathrm{K}$, nas faces. Foi possível aproximar até $5 \mathrm{~mm}$ da face quente do molde sem ocorrer a fusão. Em alguns pontos mais críticos foram instalados termopares na mesma distância do topo do molde, porém a $6,7 \mathrm{~mm}$ da face quente.

Os termopares ficaram mais concentrados na região superior do molde, uma vez que as variações de temperatura são mais significativas nessa região. Com essas informações, foram dispostos os termopares. E importante salientar também que os termopares foram divididos por regiões em cada face, separadas da seguinte maneira: centro, extremidade e entre o centro e a extremidade. Essa separação permitiu analisar as regiões mais críticas do molde. A posição dos termopares e as faces do molde estão representadas na Figura 2.

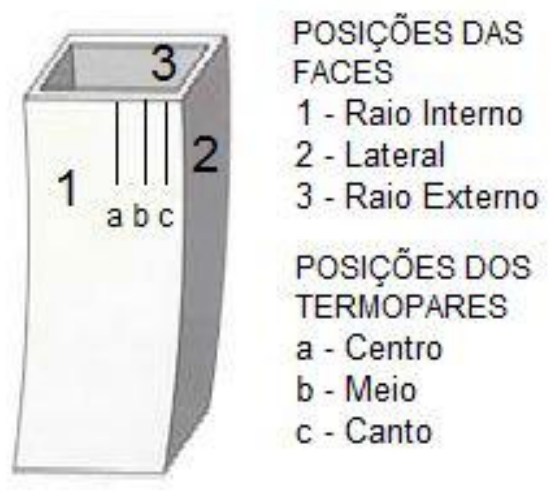

Figura 2. Representação das faces do molde e as posições relativas aos termopares.

\subsection{Velocidade de Lingotamento}

Conforme Chow [11], a transferência de calor é afetada pela velocidade de lingotamento do material. Para essa análise, foram analisadas três corridas do mesmo material, porém com velocidades de lingotamento diferentes. É importante ressaltar que a temperatura de vazamento é ligada diretamente à velocidade de lingotamento, ou seja, o aço líquido, na temperatura adequada, não pode ultrapassar certa velocidade porque pode gerar problemas como breakout [6] e não deve ter uma baixa velocidade para poder passar pelo molde sem maiores problemas de defeitos superficiais [5]. As corridas selecionadas para este trabalho estão apresentadas na Tabela 1.

Tabela 1. Corridas utilizadas para avaliação do efeito da velocidade de lingotamento na transferência de calor

\begin{tabular}{ccccc}
\hline Corrida & Qualidade & $\begin{array}{c}\text { T de Vaz. } \\
\left({ }^{\circ} \mathrm{C}\right)\end{array}$ & $\begin{array}{c}\text { Velocidade Veio } \\
3(\mathrm{~m} / \mathrm{min})\end{array}$ & Ceq \\
\hline 1 & & 1546 & 2,07 & 0,38 \\
2 & SAE 1040 & 1526 & 2,21 & 0,39 \\
3 & & 1528 & 2,23 & 0,38 \\
\hline
\end{tabular}

\footnotetext{
* Contribuição técnica ao $69^{\circ}$ Congresso Anual da ABM - Internacional e ao 14ํㅡㄹ ENEMET - Encontro Nacional de Estudantes de Engenharia Metalúrgica, de Materiais e de Minas, 21 a 25 de julho de 2014, São Paulo, SP, Brasil.
} 


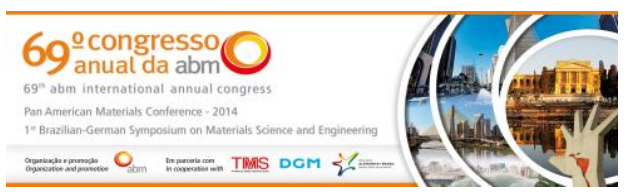

\section{RESULTADOS E DISCUSSÃO}

Os resultados obtidos pelos termopares inseridos correspondem a valores de temperatura ao longo do tempo em função da distância do topo do molde e refletem diretamente na transferência de calor. Os termopares foram identificados com um número, de acordo com sua posição. Os valores de temperaturas são dados industriais sigilosos, este artigo mostrará de maneira comparativa a transferência de calor para diferentes velocidades de lingotamento. As temperaturas observadas nos termopares foram medidas e identificadas como " $x$ ". A partir desse resultado foi designada uma escala onde " $x+10$ " significa que se está $10^{\circ} \mathrm{C}$ acima de " $\mathrm{x}$ " e assim sucessivamente. Ou seja, a variação de temperatura pode ser observada. A figura 3 exemplifica como foram obtidos os dados. Para a avaliação final, foram calculadas as temperaturas médias de cada termopar. Mais detalhes sobre a metodologia e exemplos de valores de temperaturas analisados ao longo do molde, podem ser visualizados no trabalho de Freitas [12].

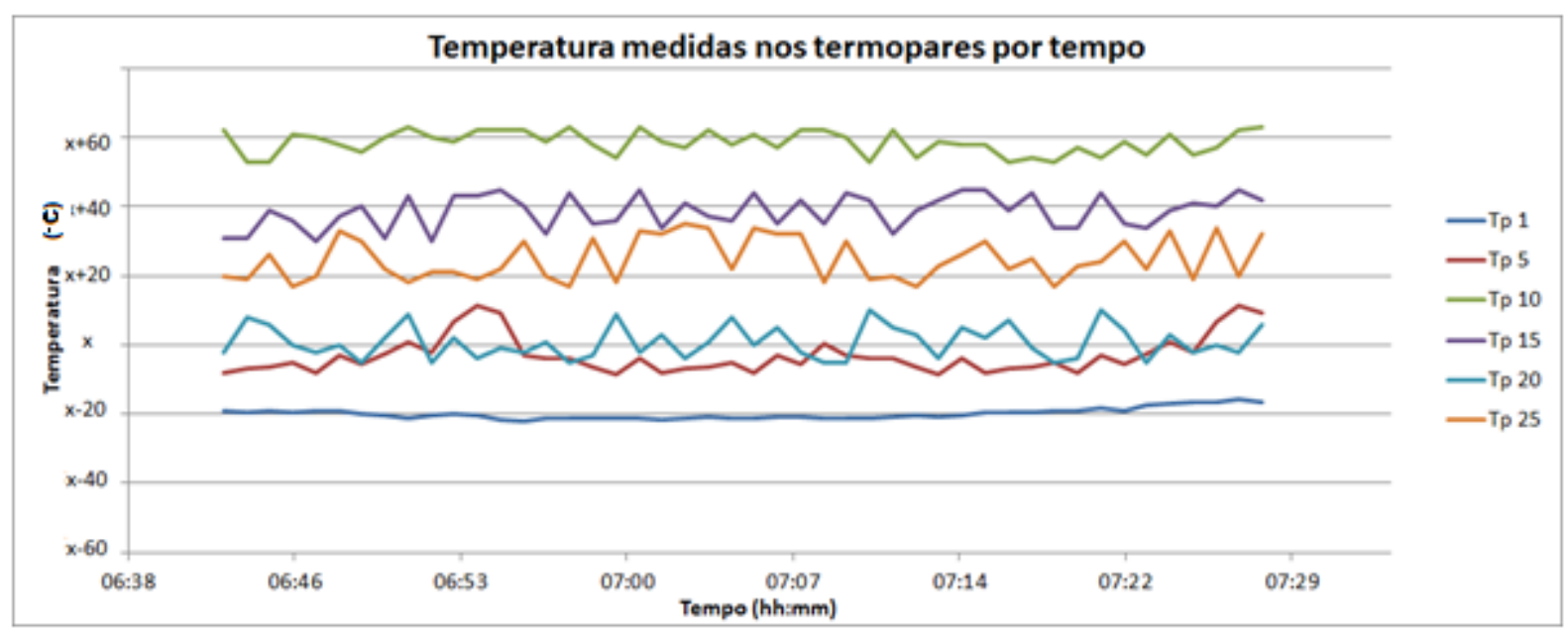

Figura 3. Temperatura $x$ tempo de termopares no molde durante lingotamento de um aço SAE 1055.

O gráfico da Figura 3 exemplifica o comportamento de alguns termopares em função do tempo em uma corrida de um aço SAE 1055. Por estarem posicionados em diferentes pontos do molde, a diferença entre as temperaturas de cada termopar é esperada. A média de cada termopar é calculada devido às pequenas variações dentro de cada curva.

A disposição dos termopares resultou em 8 gráficos, 2 para a face lateral, 3 para a face externa e 3 da face interna. As figuras 4 e 5 mostram o estudo da influência da velocidade na transferência de calor, para as faces externa e interna, com termopares dispostos nas extremidades do molde.

Os gráficos 4 e 5 condizem com o que foi estudado por Chow [11], seu trabalho mostrou que o fluxo de calor é sensível às variações de velocidade de lingotamento. Maiores velocidades de lingotamento tenderam a apresentar maiores taxas de transferência de calor. Segundo o autor, existem três razões para a velocidade de lingotamento influenciar na transferência de calor. Primeiro, o menor tempo de residência do aço em altas velocidades resulta em menor casca solidificada que deforma facilmente sob ação da pressão metalostática, reduzindo o gap de ar entre o tarugo e a parede do molde. Segundo, esse menor tempo de residência resulta em

\footnotetext{
* Contribuição técnica ao 69 Congresso Anual da ABM - Internacional e ao $14^{\circ}$ ENEMET - Encontro Nacional de Estudantes de Engenharia Metalúrgica, de Materiais e de Minas, 21 a 25 de julho de 2014, São Paulo, SP, Brasil.
} 


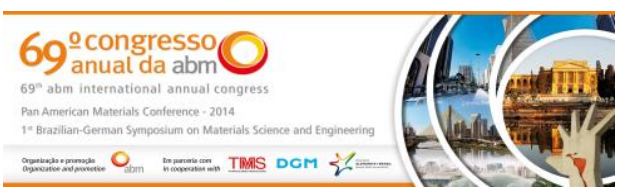

maiores temperaturas na superfície do tarugo, que aumenta o gradiente térmico e a força motriz para o fluxo de calor pelo molde. Terceiro, há uma menor contração térmica da casca solidificada devido a sua maior temperatura, que melhora o contato metal/molde por não contribuir para o aumento do tamanho do gap. Um trabalho antecedente a esse mostrou resultados semelhantes onde maiores velocidades de lingotamento apresentaram maiores temperaturas nos termopares [13], indicando maior transferência de calor. Da mesma forma, é possível verificar nas Figuras 4 e 5 temperaturas mais elevadas nos aços com maiores velocidades.

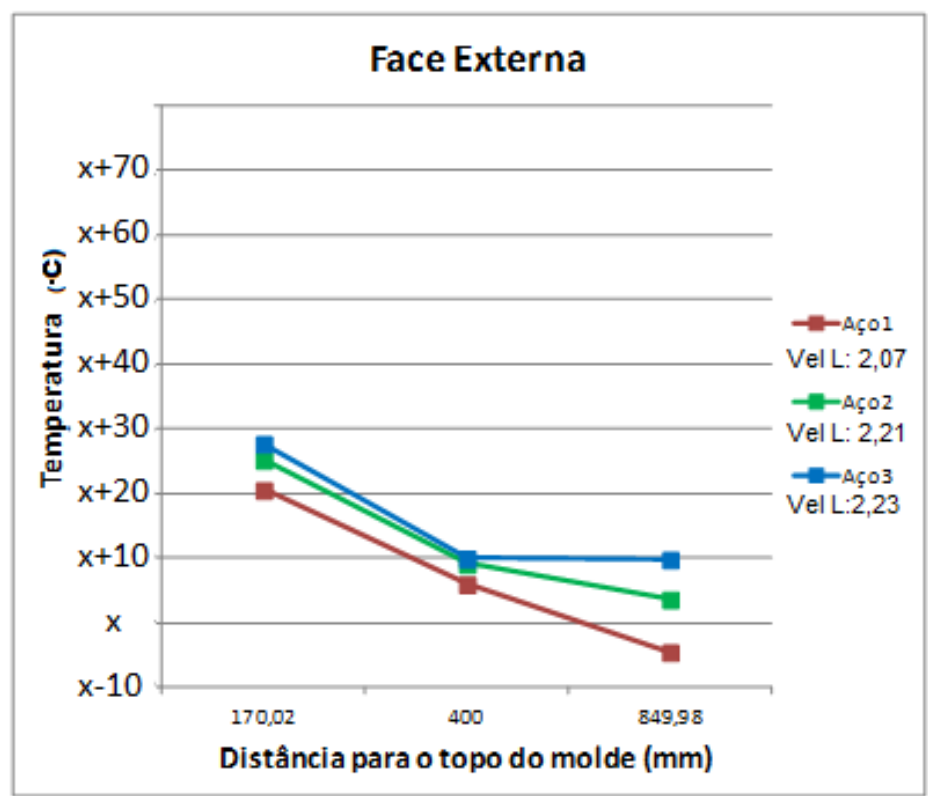

Figura 4. Curvas de Temperatura $x$ Distância do topo do molde dos termopares localizados na extremidade da face externa.

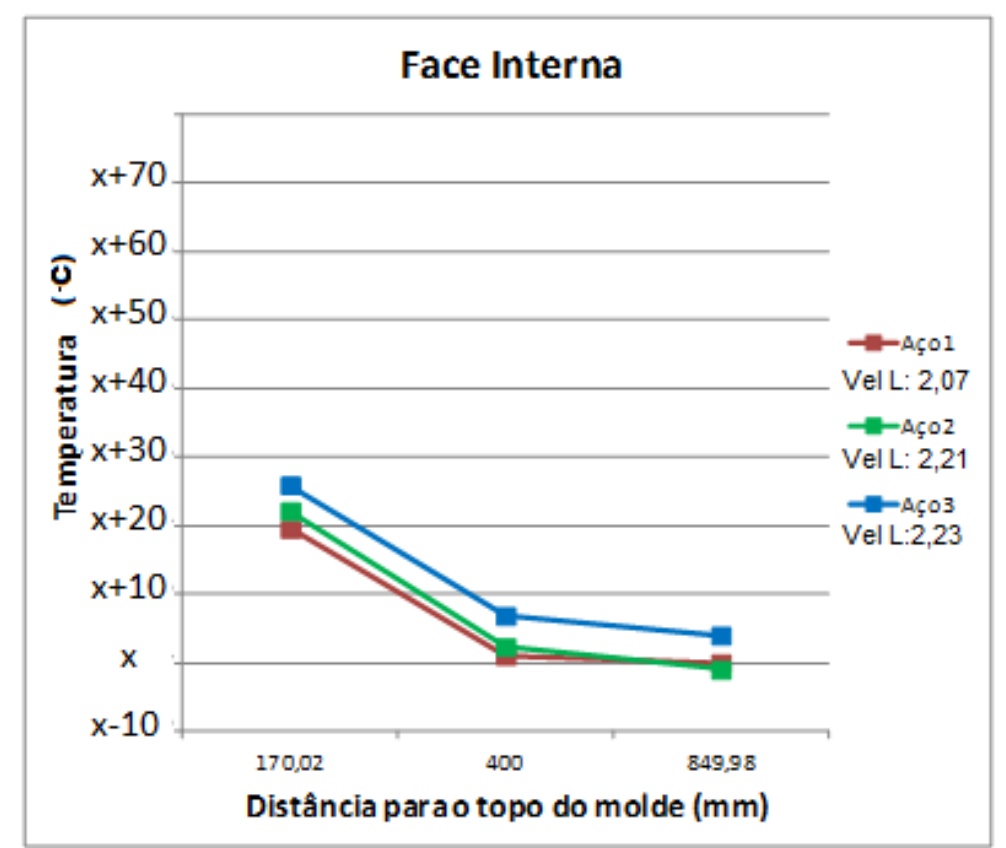

Figura 5. Curvas de Temperatura $x$ Distância do topo do molde dos termopares localizados na extremidade da face interna.

* Contribuição técnica ao 69 Congresso Anual da ABM - Internacional e ao 14을 ENEMET - Encontro Nacional de Estudantes de Engenharia Metalúrgica, de Materiais e de Minas, 21 a 25 de julho de 2014, São Paulo, SP, Brasil. 


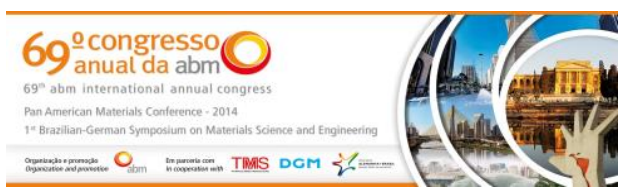

A Figura 6 mostra os resultados dos termopares localizados entre o centro e a extremidade da face do molde.

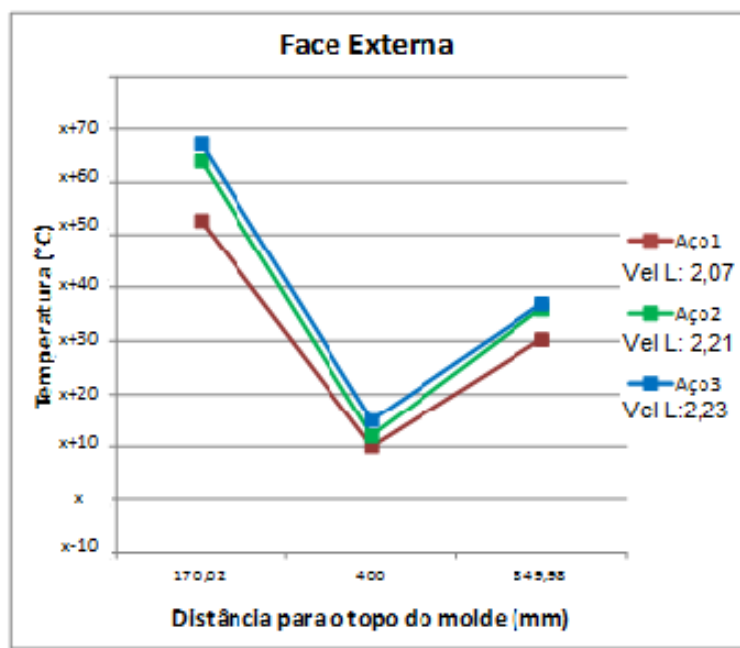

(a)
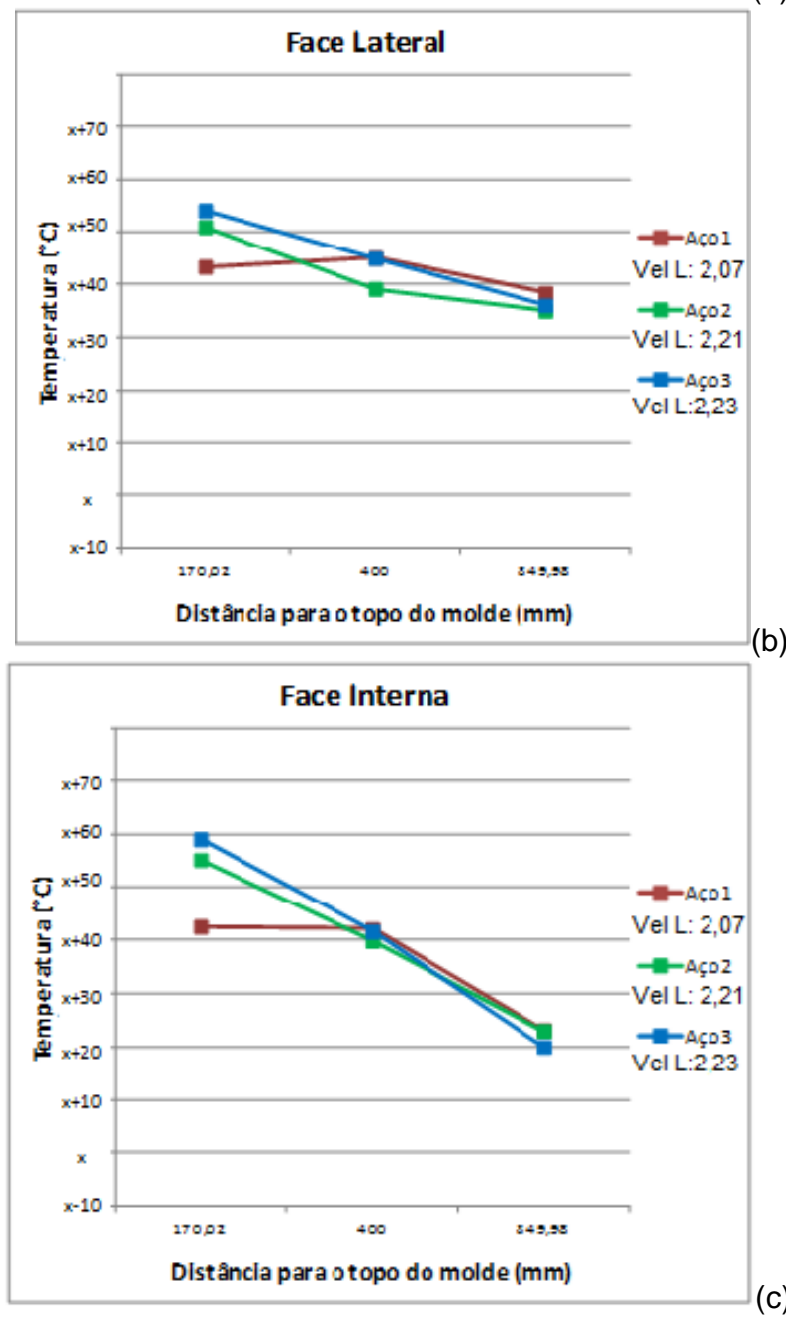

Figura 6. Curvas de Temperatura $x$ Distância do topo do molde para os termopares localizados entre o canto e o centro da face externa. / (a) Face Externa / (b) Face Lateral / (c) Face Interna.

* Contribuição técnica ao 69 Congresso Anual da ABM - Internacional e ao 14ํㅡㄹ ENEMET - Encontro Nacional de Estudantes de Engenharia Metalúrgica, de Materiais e de Minas, 21 a 25 de julho de 2014, São Paulo, SP, Brasil. 


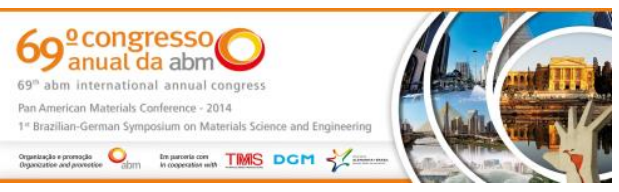

A Figura 7 representa as curvas com termopares localizados no centro da face do molde.

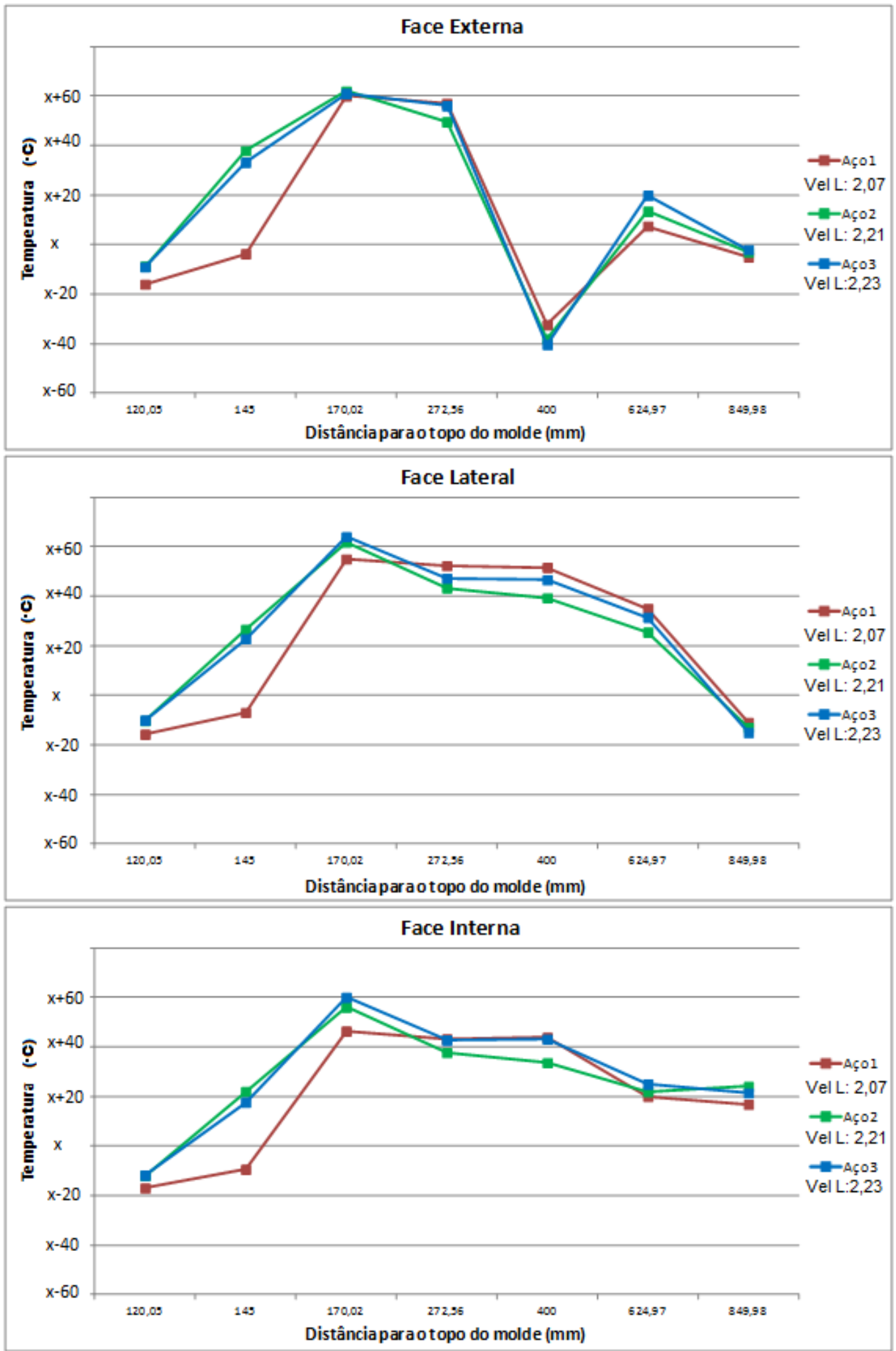

Figura 7. Curvas de Temperatura $x$ Distância do topo do molde para os termopares localizados no centro da face externa. / (a) Face Externa / (b) Face Lateral / (c) Face Interna.

A Figura 6 mostra-se novamente condizente com o estudo dos autores [11-13]. A face externa identificada na figura 6a mostra uma transferência de calor menor para 


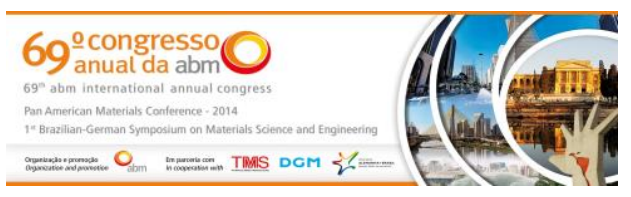

o aço 1 que apresenta uma menor velocidade de lingotamento. Os aços 2 e 3 apresentam transferência de calor mais semelhante devido as temperaturas de lingotamento serem mais próximas. A face lateral, representada pela figura $6 \mathrm{~b}$, mostra o aço 1, com uma maior transferência de calor a partir de $400 \mathrm{~mm}$ do topo do molde, isso pode ser atribuída a baixa transferência de calor inicial, que pode ter gerado uma casca muito fina que deformou-se devido a pressão metalostática. Por esse motivo o fluxo de calor é mais elevado a partir de $400 \mathrm{~mm}$. O mesmo pode ser atribuído para a face interna (Figura 6c).

A Figura 7 (a/b/c) apresenta as curvas com termopares localizados no centro das faces do molde, para as faces externa, lateral e interna, respectivamente. Observase que as maiores temperaturas ocorrem no menisco, o que significa que existe uma alta transferência de calor nessa região. Os aços 2 e 3 que apresentam velocidade e temperatura de lingotamento bem próximas, é possível perceber, novamente, que as curvas de temperatura por distância do topo do molde foram semelhantes, ou seja, a transferência de calor foi similar para esses dois aços. Para o aço 1, as temperaturas tenderam a ser constantes, para as distâncias de 170 a $400 \mathrm{~mm}$ do topo do molde isso pode ser atribuído a menor transferência de calor na região do menisco que possivelmente tenha mantido o aço com uma fina casca sólida que se deformou até $400 \mathrm{~mm}$ do topo do molde diminuindo o gap de ar.

\section{CONCLUSÕES}

Quanto à posição dos termopares em um molde para tarugos: a face externa apresentou maiores temperaturas, atestando maior transferência de calor do que as demais faces. Quanto à posição dos termopares em cada face, pode-se concluir que a maior transferência de calor ocorre na região central.

Quanto à influência da velocidade de lingotamento: para o aço avaliado, SAE 1040, o aumento da velocidade fez com que a transferência de calor fosse maior. Para o aço 1 , com velocidade de $2,07 \mathrm{~m} / \mathrm{min}$, é notado uma menor transferência de calor, principalmente na face externa (Figuras 4, 6a e 7a), onde percebe-se as menores temperaturas ao longo do comprimento do molde, isso pode ser atribuído a pressão metalostática que teve influência mais acentuada nessa face. À medida que a velocidade aumenta, percebe-se um aumento de temperatura no molde, ao longo da extensão do molde. Pode-se esperar o mesmo comportamento para outras qualidades de aço.

\section{Agradecimentos}

Os autores agradecem o apoio do Professor Jaime Spim (in memoriam), que iniciou esse trabalho. A PROBITI/FAPERGS/UFRGS pelo apoio financeiro. Em especial, ao Engenheiro Ângelo Lançanova Machado pela dedicação e ajuda na elaboração desse artigo.

\section{REFERÊNCIAS}

1 Kulkarni MS, Babu S. Managing quality in continuous casting process using product quality model and simulated annealing. Journal of Materials Processing Technology. 2005;166:294-306.

2 Araújo ES, Gasparini VM, Silva CA, Silva IA, Carvalho HC, Mansur F, Perim CA, Seshadri V. Comportamento do aço líquido na região do menisco do molde de 


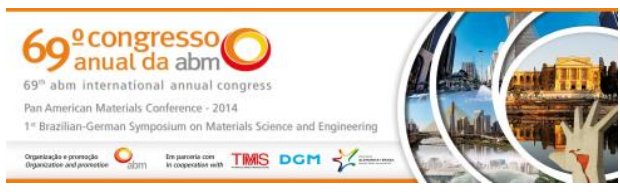

lingotamento contínuo via modelagens física e matemática. Tecnologia em Metalúrgica, Materiais e Mineração. 2010;7(1-2):18-23.

3 Vynnycky M. On the role of radiative heat transfer in air gaps in vertical continuous casting. Applied Mathematical Modelling. 2011;37:2178-88.

4 Garcia A, Spim, JA, Santos CA, Cheung N. Lingotamento Contínuo de Aços. São Paulo: Associação Brasileira de Metalurgia e Materiais; 2006.

5 Bobadilla M, Jolivet JM, Lamant JY, Larrecq M. Continuous casting of steel: a close connection between solidification studies and industrial process development. Materials Science and Engineering. 1993;173:275-285.

6 Singh SN, Blazek KE. Heat transfer and skin formation in a continuous casting mould as a function of steel carbon content. Journal of metals. 1974;26:17-27.

7 Furtmuller C, Colaneri P, Del RL. Adaptive robust stabilization of continuous casting. Automatica. 2012;48:225-232.

8 Lotov AV, Kamenev GK, Berezkin VE, Miettinen K. Optimal control of cooling process in continuous casting of steel using a visualization-based multi-criteria approach. Applied Mathematical Modelling. 2005; 29(7):653-672.

9 Incropera F. Fundamentos de Transferência de Calor e de Massa. Campinas: LTC; 2008.

10 Garcia A. Solidificação: Fundamentos e Aplicações. Campinas: Unicamp; 2001.

11 Chow C. The effects of high speed casting on the mould heat transfer, billet solidification, and mould taper design of continuously cast steel billets [doctor thesis]. British Columbia: University of the British Columbia; 2001.

12 Freitas BB. Análise da influência de parâmetros de lingotamento na transferência de calor durante a solidificação de aços especiais [trabalho de conclusão de curso]. Porto Alegre: Universidade Federal do Rio Grande do Sul; 2013.

13 Barcellos VK. Análise da transferência de calor durante a solidificação de aços em moldes de lingotamento contínuo [tese de mestrado]. Porto Alegre: Universidade Federal do Rio Grande do Sul; 2007. 